\title{
Interactions Between Remimazolam and Propofol in Combination With Sufentanil for Anesthesia During Gastroscopy
}

Song Lyu ( $\square$ Issjk1@126.com )

Second Affiliated Hospital of Hainan Medical University

Qingchun Deng

Second Affiliated Hospital of Hainan Medical University

Weixin Lin

Second Affiliated Hospital of Hainan Medical University

Xiaofang Wu

Second Affiliated Hospital of Hainan Medical University

\section{Research Article}

Keywords: Drug synergism, Gastroscopy, Propofol, Remimazolam, Sufentanil

Posted Date: November 8th, 2021

DOI: https://doi.org/10.21203/rs.3.rs-1035688/v1

License: (c) (i) This work is licensed under a Creative Commons Attribution 4.0 International License. Read Full License 


\section{Abstract \\ Background}

This study was conducted to determine how remimazolam and propofol interact when given with sufentanil.

\section{Methods}

In this single-arm study, patients were assigned to one of five groups. The sample size was not determined in advance. When the median effective dose $\left(\mathrm{ED}_{50}\right)$ and $95 \%$ confidence intervals were calculated, participants were stopped. The study included 159 patients who were scheduled for a gastrointestinal endoscopic examination and had an American Society of Anesthesiologists physical status of I/II. Patients were intravenously administered sufentanil $(0.1 \mu \mathrm{g} / \mathrm{kg})$, along with different doses of remimazolam and propofol depending on the group to which they were assigned. The endpoint for an effective response was the disappearance of the bilateral eyelash reflex. The up-and-down method was used to determine the $\mathrm{ED}_{50}$ within each treatment group. The $\mathrm{ED}_{50}$ deviations from the additive line were analyzed using isoradiometric analysis. The interaction coefficients were calculated by algebraic analysis. Interval estimation is used in statistical inference.

\section{Results}

In combination with sufentanil, the $\mathrm{ED}_{50}$ of remimazolam and propofol was determined to be 0.065 $(0.057-0.074) \mathrm{mg} / \mathrm{kg}$ and $0.657(0.590-0.724) \mathrm{mg} / \mathrm{kg}$, respectively. After sufentanil administered, when $0.25,0.5$, and $0.75 \mathrm{ED}_{50}$ remimazolam were given in combination with propofol, the interaction coefficients were 1.03,1.2and 1.08, respectively.

\section{Conclusions}

The dose of propofol with remimazolam may need to be reduced regardless of the additive or synergistic effect. There was a strong synergistic effect when the dose ratio of the two drugs was about 6:1 in $\mathrm{mg} / \mathrm{kg}$.

\section{Trial registration:}

The project was retrospectively registered on October 26, 2021 in Chinese clinical trial center with the registration number of ChiCTR2100052425.

\section{Background}


Remimazolam, a novel short-term sedative and anesthetic benzodiazepine, is effective and safe; however, it is metabolized faster than midazolam [1]. Midazolam acts synergistically with propofol in inducing anesthesia [2, 3]. Synergistic effects have been reported when midazolam and propofol were used in combination with alfentanil [4].Sufentanil is a commonly used analgesic in gastroscopy [5]. The duration of gastrointestinal endoscopy is short, which is convenient to observe drug effects and potential adverse reactions.

Rememazolam, currently used as painless gastroenteroscopy anesthetic, can be possibly used in combination with propofol and potent opioids for anesthesia induction in other clinical conditions. To use drugs accurately, we need to see if there is any synergy between remimazolam and propofol, and if so, what the synergy coefficient is.

\section{Methods}

We intend to evaluate the interaction between remimazolam and propofol when combined with sufentanil by isoradiometric analysis. To minimize the discomfort of patients, we believe that the disappearance of eyelash reflex is the endpoint of anesthesia induction [6]. Before inserting the endoscope, propofol was given immediately to deepen the anesthesia according to the ongoing examination or operation.

\section{Patients}

The study was approved by the Clinical Investigation Committee of Hainan Medical University's Second Affiliated Hospital. The up-and-down method can significantly reduce the number of subjects required for the study $[7,8$,$] . The sample size was not determined in advance because this was an adaptive clinical$ study, and it was adjusted based on certain criteria. [9]When the $\mathrm{ED}_{50}$ and $95 \%$ confidence intervals were calculated, participants were stopped.

Patients were excluded from the study if they had: 1 . anemia (hemoglobin $<90 \mathrm{~g} / \mathrm{L}$ ), 2 . albumin levels $<$ $30 \mathrm{~g} / \mathrm{L}$, 3. platelet count $<50 \times 10^{9} / \mathrm{L}, 4$. anticipated difficult airway, 5 . obvious respiratory or circulatory dysfunction before the procedure, 6 . severe neuropsychiatric disease, 7 . allergies or contraindications for the use of benzodiazepines, opioids, propofol, flumazenil, naloxone or other drugs and their components, and 8. taken similar drugs recently.

Patients who had an American Society of Anesthesiologists physical status of $\mathrm{I} / \mathrm{II}$ and were scheduled for gastrointestinal endoscopy were included in the study, and they all gave their informed consent.

\section{Intervention and Measurements}

Patients were assigned to group A (administered remimazolam in combination with $0.1 \mu \mathrm{g} / \mathrm{kg}$ sufentanil), B (administered propofol in combination with $0.1 \mu \mathrm{g} / \mathrm{kg}$ sufentanil), C (administered propofol in combination with $0.1 \mu \mathrm{g} / \mathrm{kg}$ sufentanil and 0.25 median effective dose $\left(E_{50}\right)$ remimazolam), $D$ 
(administered propofol in combination with $0.1 \mu \mathrm{g} / \mathrm{kg}$ sufentanil and $0.5 \mathrm{ED}_{50}$ remimazolam), or $\mathrm{E}$ (administered propofol in combination with $0.1 \mu \mathrm{g} / \mathrm{kg}$ sufentanil and $0.75 \mathrm{ED}_{50}$ remimazolam).

An intravenous line was secured in the waiting area. The patient's blood pressure, electrocardiogram, and oxygen saturation were monitored after entering the endoscopy suite. The administration time was determined based on the results of a pretest.

The patients were intravenously administered $0.1 \mu \mathrm{g} / \mathrm{kg}$ sufentanil (01A10011, Sichuan Renfu, China) over $10 \mathrm{~s}$, and the cannula was flushed with saline ( $5 \mathrm{~mL})$. After 90 seconds, the drug was administered according to the dose required by the grouping.

Remimazolam (201114AK, Jiang Su Heng Rui, China) was diluted to $0.5 \mathrm{mg} / \mathrm{mL}$ with normal saline. A dose-proportional to the patient's body weight was administered intravenously over $10 \mathrm{~s}$, and the cannula was flushed with $5 \mathrm{~mL}$ normal saline.

Propofol (2011171, Si Chuan Guor Rui, China) was diluted to 1, 2, and $10 \mathrm{mg} / \mathrm{mL}$ with normal saline and was administered $20 \mathrm{~s}$ after the administration of remimazolam. The observation time was 1 min after the administration of propofol.

To minimize any discomfort to patients, the disappearance of the eyelash reflex was considered the endpoint for anesthesia induction. Propofol was given shortly before endoscopy to deepen the anesthesia based on the procedure.

For the up-and-down method [10], the first patient in a group was administered a dose of the drug that was close to the $\mathrm{ED}_{50}$. If the first patient lost consciousness, the second patient was administered a smaller dose; if the first patient did not lose consciousness, the second was given a higher dose. As the procedure was repeated with more patients, the mean of the doses administered tended towards the $\mathrm{ED}_{50}$ value. According to references [11] and pre-experimental results, the increment/decrement ratio was determined to be 1:0.8.

\section{Statistical analysis}

Age and weight are presented as medians and interquartile ranges. Using SPSS version 22 (IBM Corporation, USA), the $\mathrm{ED}_{50}$ and $95 \%$ confidence intervals were calculated by probit regression analysis [10]. Interval estimation is used in statistical inference.

The statistical significance of $\mathrm{ED}_{50}$ deviation from the additive line was analyzed using isoradiometric analysis. The equation of the additive line was obtained using the $\mathrm{ED}_{50}$ values of remimazolam $(0.065$ $\mathrm{mg} / \mathrm{kg}$ ) and propofol $(0.657 \mathrm{mg} / \mathrm{kg})$ (Fig. 1). This was calculated as: $Y=-10.108 \mathrm{x}+0.657$.

The lower limits of the $95 \%$ Cls of the $\mathrm{ED}_{50}$ s of remimazolam $(0.057 \mathrm{mg} / \mathrm{kg})$ and propofol $(0.59 \mathrm{mg} / \mathrm{kg})$ were used to calculate the lower limit of the additive line's $95 \% \mathrm{Cl}$. The equation for this was found to be: $\mathrm{Y}=-10.351 \mathrm{x}+0.59$ 
The upper limits of the $95 \%$ Cls of the $\mathrm{ED}_{50}$ s of remimazolam $(0.074 \mathrm{mg} / \mathrm{kg})$ and propofol $(0.724 \mathrm{mg} / \mathrm{kg})$ were used to calculate the upper limit of the $95 \% \mathrm{Cl}$ additive line. The equation for this was found to be: $Y$ $=-9.7838 x+0.724$.

The interaction coefficients were calculated by algebraic analysis.

\section{Results}

A total of 159 patients were included in the study based on the inclusion and exclusion criteria. The number of patients in group A-E was 27, 34, 29, 39, and 28 respectively. There were no significant differences in the age and weight of patients in the five groups (Table区).

Table I. Dose gradients of remimazolam and propofol and patients' baseline characteristics. 


\begin{tabular}{|c|c|c|c|c|c|c|}
\hline Group & $\begin{array}{l}\text { Remimazolam } \\
(\mathrm{mg} / \mathrm{kg})\end{array}$ & $\begin{array}{l}\text { Propofol } \\
(\mathrm{mg} / \mathrm{kg})\end{array}$ & $n$ & $\begin{array}{l}\text { No eye } \\
\text { opening }\end{array}$ & $\begin{array}{l}\text { Age } \\
\text { [y, } \\
\text { Q2(IQR)] }\end{array}$ & $\begin{array}{l}\text { Weight } \\
\text { [kg, } \\
\text { Q2(IQR)] }\end{array}$ \\
\hline \multirow[t]{4}{*}{ A } & 0.1 & 0 & 2 & 2 & $54(17)$ & $57(14)$ \\
\hline & 0.08 & 0 & 6 & 5 & & \\
\hline & 0.064 & 0 & 12 & 7 & & \\
\hline & 0.051 & 0 & 7 & 0 & & \\
\hline \multirow[t]{4}{*}{ B } & 0 & 0.9 & 5 & 5 & $51(17.5)$ & $61(21)$ \\
\hline & 0 & 0.72 & 14 & 10 & & \\
\hline & 0 & 0.58 & 12 & 3 & & \\
\hline & 0 & 0.46 & 3 & 0 & & \\
\hline \multirow[t]{4}{*}{ C } & 0.016 & 0.62 & 7 & 7 & 53.5(13.8) & $55.5(17.5)$ \\
\hline & 0.016 & 0.49 & 13 & 6 & & \\
\hline & 0.016 & 0.39 & 7 & 2 & & \\
\hline & 0.016 & 0.32 & 2 & 0 & & \\
\hline \multirow[t]{5}{*}{ D } & 0.033 & 0.31 & 2 & 2 & $50.5(20.8)$ & $57.3(14)$ \\
\hline & 0.033 & 0.25 & 9 & 8 & & \\
\hline & 0.033 & 0.20 & 15 & 9 & & \\
\hline & 0.033 & 0.16 & 11 & 2 & & \\
\hline & 0.033 & 0.13 & 2 & 0 & & \\
\hline \multirow[t]{4}{*}{$E$} & 0.049 & 0.15 & 6 & 6 & $51.5(16.8)$ & $60(15.5)$ \\
\hline & 0.049 & 0.12 & 12 & 6 & & \\
\hline & 0.049 & 0.10 & 8 & 3 & & \\
\hline & 0.049 & 0.08 & 2 & 0 & & \\
\hline
\end{tabular}

Patients in group A were administered remimazolam in combination with $0.1 \mu \mathrm{g} / \mathrm{kg}$ sufentanil to determine the $\mathrm{ED}_{50}$ of remimazolam in this combination. Intra-group remimazolam efficacy measurements were carried out with a 1:0.8 increments/decrement ratio. In the pretest, the $\mathrm{ED}_{50}$ of remimazolam was estimated to be $0.08 \mathrm{mg} / \mathrm{kg}$; hence, this was taken as the intermediate dose. Doses of 
$0.125,0.1,0.08,0.064$, and $0.051 \mathrm{mg} / \mathrm{kg}$ were chosen for evaluation (Table 1 ). The $\mathrm{ED}_{50}$ of remimazolam was found to be $0.065 \mathrm{mg} / \mathrm{kg}$ (Cl: $0.057-0.074 \mathrm{mg} / \mathrm{kg}$ ) in combination with $0.1 \mu \mathrm{g} / \mathrm{kg}$ sufentanil.

Patients in group B were administered propofol in combination with $0.1 \mu \mathrm{g} / \mathrm{kg}$ sufentanil for the determination of propofol $\mathrm{ED}_{50}$ in this combination. Naguib and coworkers reported that propofol has an $\mathrm{ED}_{50}$ value of $0.9 \mathrm{mg} / \mathrm{kg}$ in this combination [12]. Based on these data and using the 1:0.8

increment/decrement ratio, the selected doses of propofol were $1.41,1.13,0.9,0.72,0.58$, and $0.46 \mathrm{mg} / \mathrm{kg}$ (Table 1). The $\mathrm{ED}_{50}$ of propofol was found to be $0.657 \mathrm{mg} / \mathrm{kg}$ (Cl: $0.59-0.724 \mathrm{mg} / \mathrm{kg}$ ) when used in combination with $0.1 \mu \mathrm{g} / \mathrm{kg}$ sufentanil(Fig. 1).

The $\mathrm{ED}_{50}$ of propofol was determined in groups C-E using the same method as group $\mathrm{B}$. Thus, the $\mathrm{ED}_{50}$ of propofol in combination with $0.1 \mu \mathrm{g} / \mathrm{kg}$ sufentanil and doses of $0.25,0.5$, and $0.75 \mathrm{ED}_{50} \mathrm{~s}$ of remimazolam were evaluated.

Group C patients were administered $0.1 \mu \mathrm{g} / \mathrm{kg}$ sufentanil, 0.25 ED $_{50}(0.016 \mathrm{mg} / \mathrm{kg})$ remimazolam, and varying propofol doses. The propofol $0.75 \mathrm{ED}_{50}(0.49 \mathrm{mg} / \mathrm{kg})$ was chosen as the central point. The propofol ED ${ }_{50}$ value was $0.476 \mathrm{mg} / \mathrm{kg}$ (Cl: $\left.0.411-0.545 \mathrm{mg} / \mathrm{kg}\right)$

Group D patients were administered $0.1 \mu \mathrm{g} / \mathrm{kg}$ sufentanil, $0.5 \mathrm{ED}_{50}(0.033 \mathrm{mg} / \mathrm{kg})$ remimazolam, and varying propofol doses. The 0.5 The $\mathrm{ED}_{50}$ of propofol $(0.25 \mathrm{mg} / \mathrm{kg})$ was used as the central point. The propofol $\mathrm{ED}_{50}$ value was $0.194 \mathrm{mg} / \mathrm{kg}(\mathrm{Cl}: 0.171-0.217 \mathrm{mg} / \mathrm{kg})$.

Group E patients were administered $0.1 \mu \mathrm{g} / \mathrm{kg}$ sufentanil, 0.75 ED $_{50}(0.049 \mathrm{mg} / \mathrm{kg})$ remimazolam, and varying propofol doses. The 0.25 The $\mathrm{ED}_{50}$ of propofol $(0.15 \mathrm{mg} / \mathrm{kg})$ was used as the central. The propofol $\mathrm{ED}_{50}$ value was $0.114 \mathrm{mg} / \mathrm{kg}(\mathrm{Cl}: 0.095-0.132 \mathrm{mg} / \mathrm{kg})$.

An isoradiometric diagram (Fig. 2) and algebraic analysis (Table $₫$ ) showed that the synergistic coefficients of remimazolam and propofol were 1.03,1.26, and 1.08with doses of remimazolam equivalent to $0.25,0.5$, and $0.75 \mathrm{ED}_{50} \mathrm{~s}$, respectively, in combination with sufentanil $(0.1 \mu \mathrm{g} / \mathrm{kg})$. The synergy coefficient of group $\mathrm{E}$ was 1.08 , but the $95 \% \mathrm{Cl}$ of the propofol dose was within the $95 \% \mathrm{Cl}$ of additive action (Fig. 2).

Table II. Interactions of remimazolam and propofol, in combination with $0.1 \mu \mathrm{g} / \mathrm{kg}$ sufentanil, evaluated through observation of eyelash reflex inhibition. 


\begin{tabular}{|c|c|c|c|c|c|c|c|}
\hline \multirow[t]{2}{*}{ Group } & \multicolumn{2}{|c|}{ Remimazolam } & \multicolumn{2}{|l|}{ Propofol } & \multirow{2}{*}{$\begin{array}{l}\text { Coefficient } \\
\text { sum }\end{array}$} & \multirow{2}{*}{$\begin{array}{l}\text { Expected } \\
\text { value of } \\
\text { additive } \\
\text { action }\end{array}$} & \multirow{2}{*}{$\begin{array}{l}\text { Interaction } \\
\text { coefficient }\end{array}$} \\
\hline & $\begin{array}{l}\text { ED50 } \\
\text { coefficient }\end{array}$ & $\begin{array}{l}\text { ED50 } \\
(\mathrm{mg} / \mathrm{kg})\end{array}$ & $\begin{array}{l}\text { ED50 } \\
\text { coefficient }\end{array}$ & $\begin{array}{l}\text { ED50 } \\
(\mathrm{mg} / \mathrm{kg})\end{array}$ & & & \\
\hline A & 1 & $\begin{array}{l}0.065 \\
(0.057- \\
0.074)\end{array}$ & 0 & 0 & 1 & 1 & 1 \\
\hline B & 0 & 0 & 1 & $\begin{array}{l}0.657 \\
(0.590- \\
0.724)\end{array}$ & 1 & 1 & 1 \\
\hline C & 0.25 & 0.016 & 0.725 & $\begin{array}{l}0.476 \\
(0.411- \\
0.545)\end{array}$ & 0.975 & 1 & $\begin{array}{l}1.03 \\
(p=0.154)\end{array}$ \\
\hline D & 0.5 & 0.033 & 0.295 & $\begin{array}{l}0.194 \\
(0.171- \\
0.217)\end{array}$ & 0.795 & 1 & $\begin{array}{l}1.20 \\
(p=0.000)\end{array}$ \\
\hline$E$ & 0.75 & 0.049 & 0.174 & $\begin{array}{l}0.114 \\
(0.095- \\
0.132)\end{array}$ & 0.924 & 1 & $\begin{array}{l}1.08 \\
(p=0.000)\end{array}$ \\
\hline
\end{tabular}

The table shows median effective dose (ED50) equivalent doses of remimazolam and propofol in combination with $0.1 \mu \mathrm{g} / \mathrm{kg}$ sufentanil.

\section{Discussion}

Drug synergism is attributed to pharmacodynamic or pharmacokinetic interactions [13]. When $0.5 \mathrm{ED}_{50}$ remimazolam was combined with propofol, it produced a synergistic effect in group D. As the metabolic pathways of remimazolam and propofol are different, there is no metabolic interference, suggesting that this synergy occurs after the two drugs bind to the receptor.

Remimazolam and propofol showed an additive effect only in groups $C$ and $E$. At $0.25 E D_{50}$, the plasma drug concentration of remimazolam or propofol was near the threshold concentration. Since both the drugs metabolize rapidly, the effects were short-lived. Before the synergistic effect can be observed, the drug will be eliminated. The occupied receptor is less and the efficacy is weakened, so it only shows additive effect.

The interaction coefficient of the combination was the highest at a dose equivalent to $0.5 \mathrm{ED}_{50}$ of remimazolam. As shown in Table 2, the dose of remimazolam divided by the dose of propofol in group $D$ is about 1:6. This implies that there is a synergistic effect when the dose ratio of remimazolam and propofol is about $1: 6 \mathrm{mg} / \mathrm{kg}$. 
Table 2

Interactions of remimazolam and propofol, in combination with $0.1 \mathrm{~g} / \mathrm{kg}$ sufentanil, evaluated through observation of eyelash reflex inhibition.

\begin{tabular}{|c|c|c|c|c|c|c|}
\hline Group & $\begin{array}{l}\text { Remimazolam } \\
(\mathrm{mg} / \mathrm{kg})\end{array}$ & $\begin{array}{l}\text { Propofol } \\
\text { (mg/kg) }\end{array}$ & $\mathrm{n}$ & $\begin{array}{l}\text { No eye } \\
\text { opening }\end{array}$ & $\begin{array}{l}\text { Age } \\
{[y,} \\
\text { Q2(IQR)] }\end{array}$ & $\begin{array}{l}\text { Weight } \\
\text { [kg, } \\
\text { Q2(IQR)] }\end{array}$ \\
\hline \multirow[t]{4}{*}{ A } & 0.1 & 0 & 2 & 2 & $54(17)$ & $57(14)$ \\
\hline & 0.08 & 0 & 6 & 5 & & \\
\hline & 0.064 & 0 & 12 & 7 & & \\
\hline & 0.051 & 0 & 7 & 0 & & \\
\hline \multirow[t]{4}{*}{ B } & 0 & 0.9 & 5 & 5 & $51(17.5)$ & $61(21)$ \\
\hline & 0 & 0.72 & 14 & 10 & & \\
\hline & 0 & 0.58 & 12 & 3 & & \\
\hline & 0 & 0.46 & 3 & 0 & & \\
\hline \multirow[t]{4}{*}{ C } & 0.016 & 0.62 & 7 & 7 & $53.5(13.8)$ & $55.5(17.5)$ \\
\hline & 0.016 & 0.49 & 13 & 6 & & \\
\hline & 0.016 & 0.39 & 7 & 2 & & \\
\hline & 0.016 & 0.32 & 2 & 0 & & \\
\hline \multirow[t]{5}{*}{ D } & 0.033 & 0.31 & 2 & 2 & $50.5(20.8)$ & $57.3(14)$ \\
\hline & 0.033 & 0.25 & 9 & 8 & & \\
\hline & 0.033 & 0.20 & 15 & 9 & & \\
\hline & 0.033 & 0.16 & 11 & 2 & & \\
\hline & 0.033 & 0.13 & 2 & 0 & & \\
\hline \multirow[t]{4}{*}{$E$} & 0.049 & 0.15 & 6 & 6 & $51.5(16.8)$ & $60(15.5)$ \\
\hline & 0.049 & 0.12 & 12 & 6 & & \\
\hline & 0.049 & 0.10 & 8 & 3 & & \\
\hline & 0.049 & 0.08 & 2 & 0 & & \\
\hline
\end{tabular}

According to group $D$ data in Table 2, the synergy coefficient is 1.25 . It can be understood that if a patient changes from the original propofol requirement of $1 \mathrm{mg} / \mathrm{kg}$ to combined medication, the same effect can 
be achieved with only $0.3 \mathrm{mg} / \mathrm{kg}$ propofol with $0.05 \mathrm{mg} / \mathrm{kg}$ remimazolam.

As there were other adjacent dose ratios, this may lead to a stronger synergy. Therefore, further experiments are required to probe the effects of adjacent does ratios. The disappearance of the eyelash reflex is only one of the common endpoints in clinical anesthesia. The interaction of other clinical endpoints needs to be further studied and determined. The occurrence of side effects also need be observed simultaneously.

\section{Conclusions}

The dose of propofol with remimazolam may need to be reduced regardless of the additive or synergistic effect. There was a strong synergistic effect when the dose ratio of the two drugs was about 6:1 in $\mathrm{mg} / \mathrm{kg}$.

\section{Declarations}

\section{Ethics approval and consent to participate}

The study was approved by the Clinical Investigation Committee of Hainan Medical University's Second Affiliated Hospital (number/ID was LW2021001). All participants signed informed consent. All methods were performed in accordance with the relevant guidelines and regulations.

\section{Consent for publication}

"Not applicable"

\section{Availability of data and materials}

The datasets used and/or analysed during the current study are available from the corresponding author on reasonable request.

\section{Competing interests}

The authors certify that there is no conflict of interest with any financial organization regarding the material discussed in the manuscript.

\section{Funding}

This study is supported by the Hainan Provincial Health Commission (20A200247) and Project supported by Hainan Province Clinical Medical Center.

\section{Authors' contributions}


Song Lyu and Qingchun Deng contributed equally to the preparation of this manuscript.They have given substantial contributions to the conception or the design of the manuscript, analysis and interpretation of the data. All authors have participated to drafting the manuscript. All authors read and approved the final version of the manuscript.

\section{Acknowledgements}

Participating Investigator: The authors acknowledge Hu Sun who served as scientific advisor.

\section{References}

1. Pastis NJ, Yarmus LB, Schippers F, Ostroff R, Chen A, Akulian J, Wahidi M, Shojaee S, Tanner NT, Callahan SP, Feldman G, Lorch DG Jr, Ndukwu I, Pritchett MA, Silvestri GA; PAION Investigators. Safety and efficacy of remimazolam compared with placebo and midazolam for moderate sedation during bronchoscopy. Chest 2019;155(1):137-46. https://doi.org/10.1016/j.chest.2018.09.015.

2. Ong LB, Plummer JL, Waldow WC, Owen H. Timing of midazolam and propofol administration for co-induction of anaesthesia. Anaesth Intensive Care 2000;28(5):527(31. https://doi.org/10.1177/0310057X0002800507.

3. Pace NL, Stylianou MP. Advances in and limitations of up-and-down methodology: a précis of clinical use, study design, and dose estimation in anesthesia research. Anesthesiology 2007;107(1):144(52. https://doi.org/10.1097/01.anes.0000267514.42592.2a.

4. Vinik HR, Bradley EL Jr, Kissin I. Triple anesthetic combination: propofol-midazolam-alfentanil. Anesth Analg 1994;78(2):354-8. https://doi.org/10.1213/00000539-199402000-00026.

5. Zhang L, Bao Y, Shi D. Comparing the pain of propofol via different combinations of fentanyl, sufentanil or remifentanil in gastrointestinal endoscopy. Acta Cir Bras 2014;29(10):675-80. https://doi.org/10.1590/s0102-8650201400160008.

6. Xu Y, Song X, Zhang G. ED50 of dexmedetomidine nasal drip in induction of hypnosis in children during computed tomography. Zhonghua Yi Xue Za Zhi 2014;94(24):1886-8. https://doi.org/10.3760/cma.j.issn.0376-2491.2014.24.012

7. Short TG, Plummer JL, Chui PT. Hypnotic and anaesthetic interactions between midazolam, propofol and alfentanil. Br J Anaesth 1992;69(2):162-7. https://doi.org/10.1093/bja/69.2.162.

8. Chinta SS, Schrock CR, McAllister JD, Jaffe DM, Liu J, Kennedy RM. Rapid administration technique of ketamine for pediatric forearm fracture reduction: a dose-finding study. Ann Emerg Med 2015;65(6):640-8.e2. https://doi.org/10.1016/j.annemergmed.2014.12.011.

9. Yu J, Xiang B, Song Y, Chen H, Li Y, Liu C. ED50 of propofol in combination with low-dose sufentanil for intravenous anesthesia in hysteroscopy. Basic Clin Pharmacol Toxicol 2019;125(5):460(5. https://doi.org/10.1111/bcpt.13280.

10. Pace NL, Stylianou MP. Advances in and limitations of up-and-down methodology: a précis of clinical use, study design, and dose estimation in anesthesia research. Anesthesiology 2007;107(1):144(52. 
https://doi.org/10.1097/01.anes.0000267514.42592.2a.

11. Dixon WJ. The up-and-down method for small samples. J Am Stat Assoc 1965;60:967-78. https://doi.org/10.1080/01621459.1965.10480843.

12. Naguib M, Samarkandi AH, Moniem MA, Mansour EE, Alshaer AA, Al-Ayyaf HA, Fadin A, Alharby SW. The effects of melatonin premedication on propofol and thiopental induction dose-response curves: a prospective, randomized, double-blind study. Anesth Analg 2006;103(6):1448-52.

13. Pemovska T, Bigenzahn JW, Superti-Furga G. Recent advances in combinatorial drug screening and synergy scoring. Curr Opin Pharmacol 2018;42:102-10. https://doi.org/10.1016/j.coph.2018.07.008.

\section{Figures}

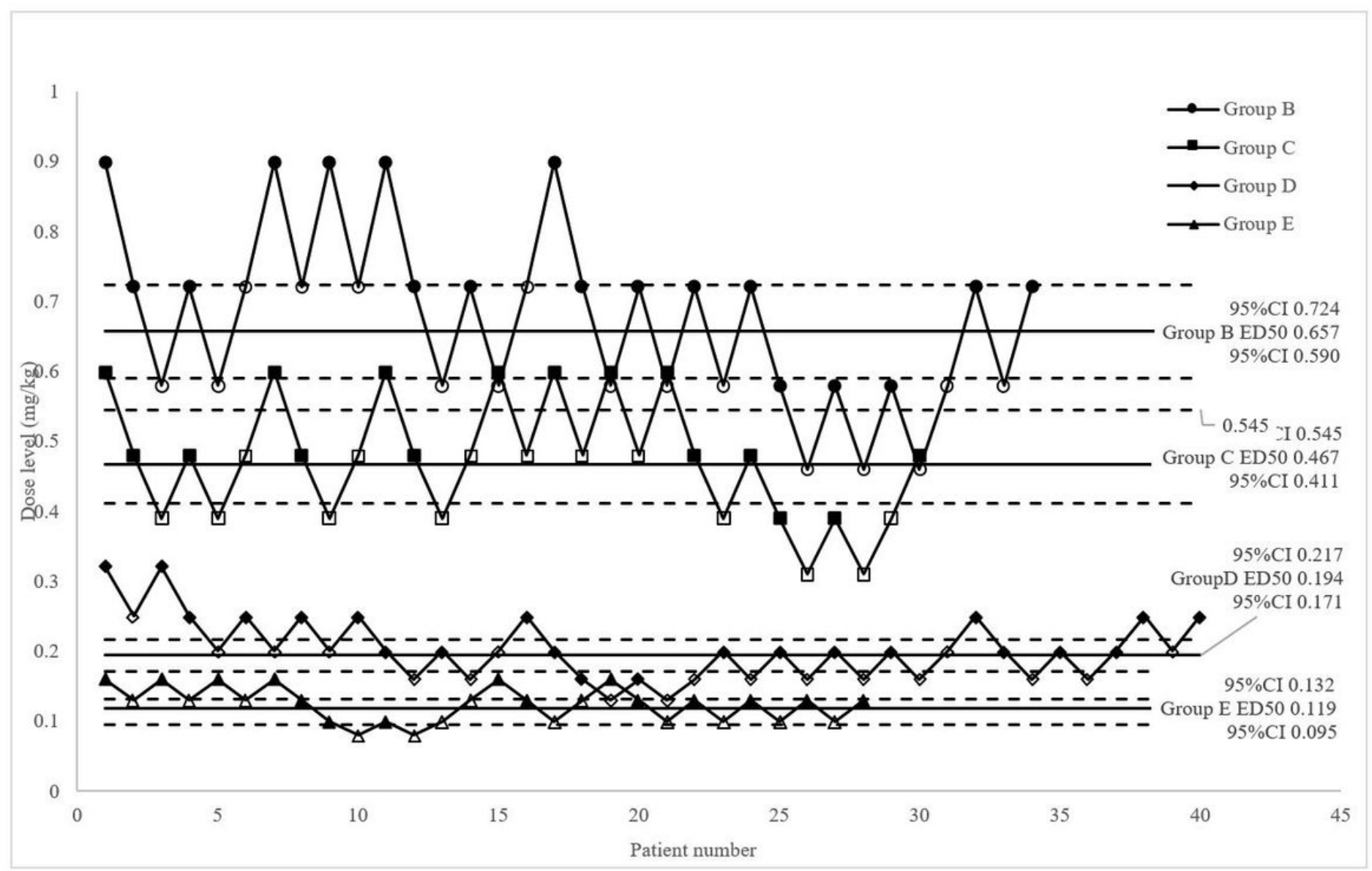

Figure 1

Determination of the median effective dose (ED50) of propofol in combination with $0.1 \mu \mathrm{g} / \mathrm{kg}$ sufentanil and varying doses $(0,0.049,0.033,0.016 \mathrm{mg} / \mathrm{kg}$ ) of remimazolam. The patient sequence number (x-axis) is the order in which patients were administered the dose as per the up-and-down design. Group $B$ assigned doses (y-axis) were $0.62,0.49,0.39$, and $0.32 \mathrm{mg} / \mathrm{kg}$ propofol. $\mathbf{G}$ Group $\mathrm{C}$ assigned doses (yaxis) were $0.9,0.72,0.58$, and $0.46 \mathrm{mg} / \mathrm{kg}$ propofol. GroupD assigned doses (y-axis) were 0.62, 0.49, 
0.39 , and $0.32 \mathrm{mg} / \mathrm{kg}$ propofol. $\Delta$ GroupE assigned doses (y-axis) were $0.31,0.25,0.20,0.16$, and 0.13 $\mathrm{mg} / \mathrm{kg}$ propofol. $\square \Delta \mathbf{\Delta}$ Effective dose (disappearance of bilateral eyelash reflex observed); $\square \diamond \Delta$ ineffective dose; - ED50; - - 95\% confidence interval of ED50.

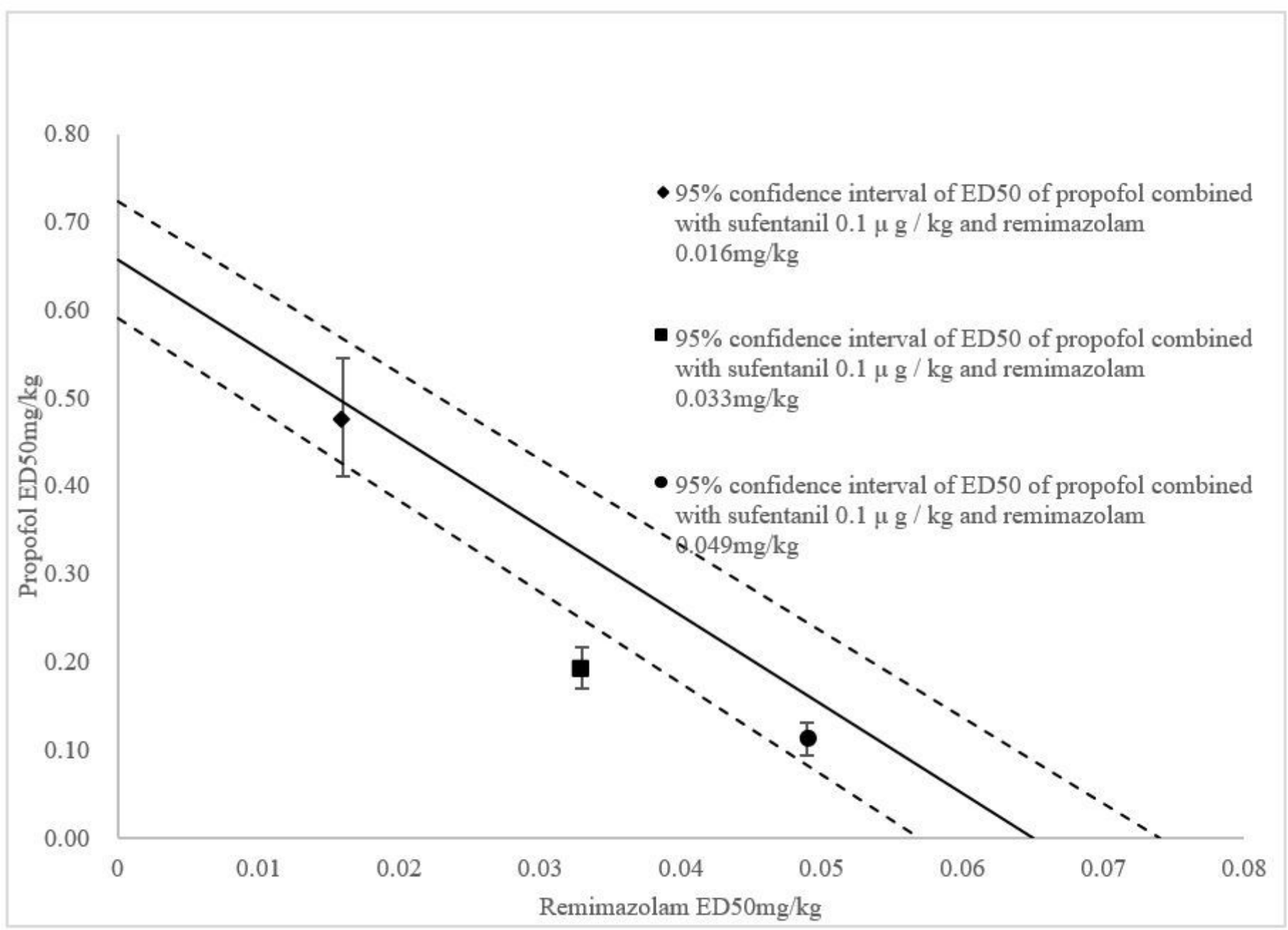

\section{Figure 2}

Isotherms of the interactions between remimazolam and propofol when administered in combination with $0.1 \mu \mathrm{g} / \mathrm{kg}$ sufentanil. Remimazolam $0.065 \mathrm{mg} / \mathrm{kg}(0.057-0.074 \mathrm{mg} / \mathrm{kg})$ and propofol $0.657 \mathrm{mg} / \mathrm{kg}$ $(0.59-0.724 \mathrm{mg} / \mathrm{kg})$ were used to calculate the equation of the additional line and the $95 \%$ confidence interval lines. The $x$-axis represents the remimazolam dose with $0.1 \mathrm{~g} / \mathrm{kg}$ sufentanil, while the $\mathrm{y}$-axis shows the propofol ED50 at this remimazolam dose. 